\title{
A Study on the Relationship Between the Income Gap Between Urban and Rural Residents and the Educational Level in China
}

\author{
Zhang Quan, Zhang Hao \\ Economics School, Shanghai University, Shanghai, China
}

Email address:

505431268@qq.com (Zhang Quan), zhangles_90@126.com (Zhang Hao)

\section{To cite this article:}

Zhang Quan, Zhang Hao. A Study on the Relationship Between the Income Gap Between Urban and Rural Residents and the Educational Level in China. International Journal of Economics, Finance and Management Sciences. Vol. 3, No. 5, 2015, pp. 630-634. doi: $10.11648 /$ j.ijefm.20150305.37

\begin{abstract}
Education and income have been affected each other, good education can get higher income; the increase of income can pay for higher education. This paper uses statistical data to describe the current situation of the income of urban and rural residents and the educational level in China, to explain that there is a significant gap on the income between urban and rural residents or the educational level, and this gap is still maintained a trend of expansion. In order to explore the relationshipbetween the income gap between urban and rural residents and the educational level in China, this paper establishes a model to carry out linear regression analysis and test, so as to determine the level of education is an important factor affecting the income gap between urban and rural residents. The Chinese government should support the development of education, and improve the overall educational level of the people. At the same time, the government should implement the policy of educational investment and educational resources to rural areas. This has a positive meaning to realize the balanced development of education and economic income and the common prosperity of urban and rural residents in China.
\end{abstract}

Keywords: Income, Educational Level, Reform in Education

\section{中国城乡居民收入差距与受教育水平关系的研究}

张权, 张昊

经济学院, 上海大学, 上海, 中国

\section{邮箱}

505431268@qq. com（张权）, zhangles_90@126.com（张昊）

\begin{abstract}
摘要：教育与收入一直互相影响，良好的教育可以获得较高的收入，收入的增加可以满足接受更高教育的投入。本文 利用统计数据表述了城乡居民收入现状和受教育现状, 来说明中国城乡居民收入水平与受教育水平存在着明显的差距, 并且这一差距仍保持着扩大的趋势。为了探究城乡居民收入差距与受教育水平的关系, 本文通过选取城乡居民收入比 值和城乡人均受教育年限比值两个指标建立模型进行线性回归分析和检验, 从而确定受教育水平是城乡居民收入差距 重要影响因素。国家做好教育改革, 对发展教育事业要大力支持, 并提高民众的整体受教育水平, 同时实行教育投资 和教育资源要向农村倾斜的政策，从战略高度抓好农村贫困地区教育发展和人口文化素质提高，这对实现教育和经济 收入的均衡发展, 改善城乡之间, 各地区之间收入差距, 实现城乡居民共同富裕有着积极意义。
\end{abstract}

关键词：收入，受教育水平，教育改革 


\section{1. 引言}

新中国成立以来，居民的收入有了根本性的改变。中 国的经济一直保持着高速稳定的发展, 人均收入也由最初 的提供温饱到如今的财富积累。但是，正是居民收入迅速 增长, 人们注意到社会的大部分财富集中在少数人的手里, 收入分配问题越来越受到人们的重视。收入差距的拉大会 使得 “贫穷” 阶层对拥有大量财富阶层抱有仇恨心态，从 而影响社会秩序的稳定。近几年来中国城乡居民收入迅速 增长, 现阶段来看它的增长速度没有降低的迹象并且城乡 居民收入差距一直不断扩大。

教育是一个国家的根本, 它不仅仅是让人们了解和适 应客观世界, 同时, 它赋予了人们维持这个世界秩序法律 和道德准则。最近一些年, 中国对教育方面的问题越来越 重视，九年义务教育的实行让偏远地区的孩子有了更多受 教育的机会。但是受教育水平的提高不能掩盖城乡教育的 差距, 在农村并不是每一个适龄儿童都有接受教育的机会, 而城市的孩子在接受义务教育的同时还有机会收到其他 的培训, 例如: 乐器、学习班、舞蹈等等。这一现象往往 在城乡收入差距越大的地区越明显, 这是一种畸形的发展 模式, 在城镇接受优越的教育的居民得到高报酬去发展城 市; 农村有机会越过“龙门”学子也大多数选择留在城市。
城市就像一块磁铁吸引大批的社会精英, 越聚越大逐渐拉 开与农村的距离。

\section{2. 中国城乡居民收入差距和受教育水平现状}

\section{1. 中国城乡居民收入现状}

\subsection{1. 城镇与农村之间居民收入}

对于城乡居民收入差距扩大这一现状中国政府通过 一系列手段, 一方面减免农村农民种地所要交的税收, 另 一方面提供各方面的政策性补贴, 虽然促使农村居民收入 提高, 但是城镇居民收入相对增长速度提升的更快。

从图1中能看出，1990-2011年中国城乡居民家庭人均 可支配收入都在一直稳定的提高, 具有相同方向变动趋势, 但在城乡居民家庭人均可支配收入水平提高的同时城乡 收入差距却越来越大。农村居民与城镇居民收入对比来说, 农村居民收入水平低、增长慢。总的来说城镇居民收入增 长速度较高于农村居民收入的增长速度, 农村居民的收入 增长缓慢, 生活水平相对较低。农村居民家庭人均收入从 1991年的686. 3增长到2011年的6977. 3元。城镇居民家庭 人均可支配收入从 1990 年的 1510.2 元提高到 2011 年的 21809. 8元。

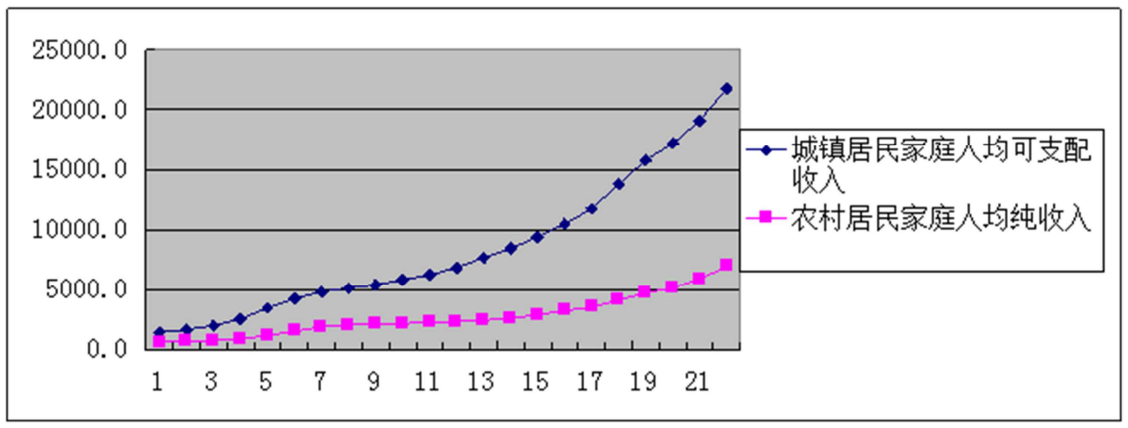

图1 1990-2011年城乡居民家庭人均收入差距折线图。

\subsection{2. 城镇与乡村各自内部之间居民收入}

除了要注意城乡之间的收入差距, 还要认识到它们各 自内部之间居民收入差距。这些差距是不可以忽略不计的, 它们一直不断被拉大。城乡间居民收入差距变化都比较明 显, 2002年城镇最高收入户比最低收入户高 16587.25 元, 前者是后者的 7.89 倍; 到了 2008 年城镇最高收入户比最低
收入户高 38860.06 元，倍数也提高到9.18倍。农村居民收 入虽然不高，但是居民间的收入差距很大，2002年农村最 高收入户比最低收入户高5038.5元，但是最高收入户仍是 最低收入户的6.89倍; 2008年收入差距增长到9790.39元, 倍数随之提高到 7.53 倍。见图 2 和图 3 。

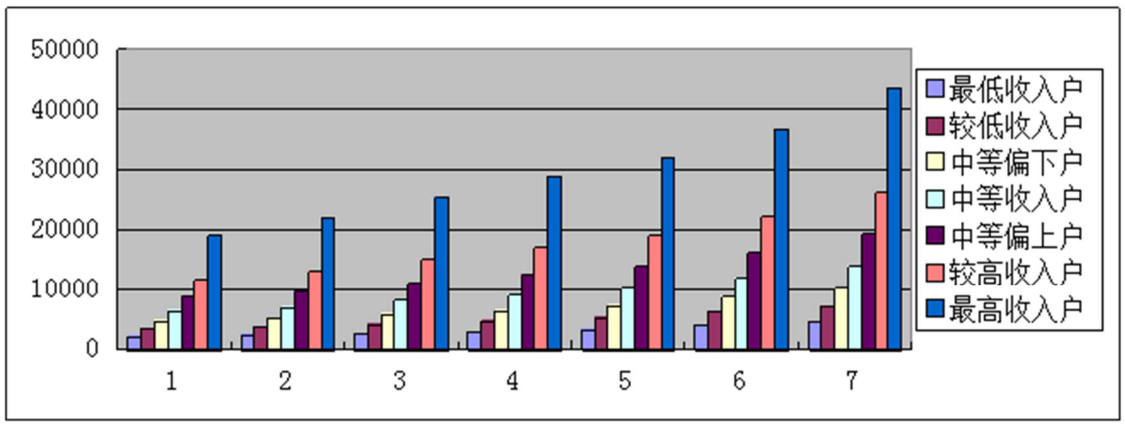

图2 2002-2008年城镇按收入等级分类柱形图。 


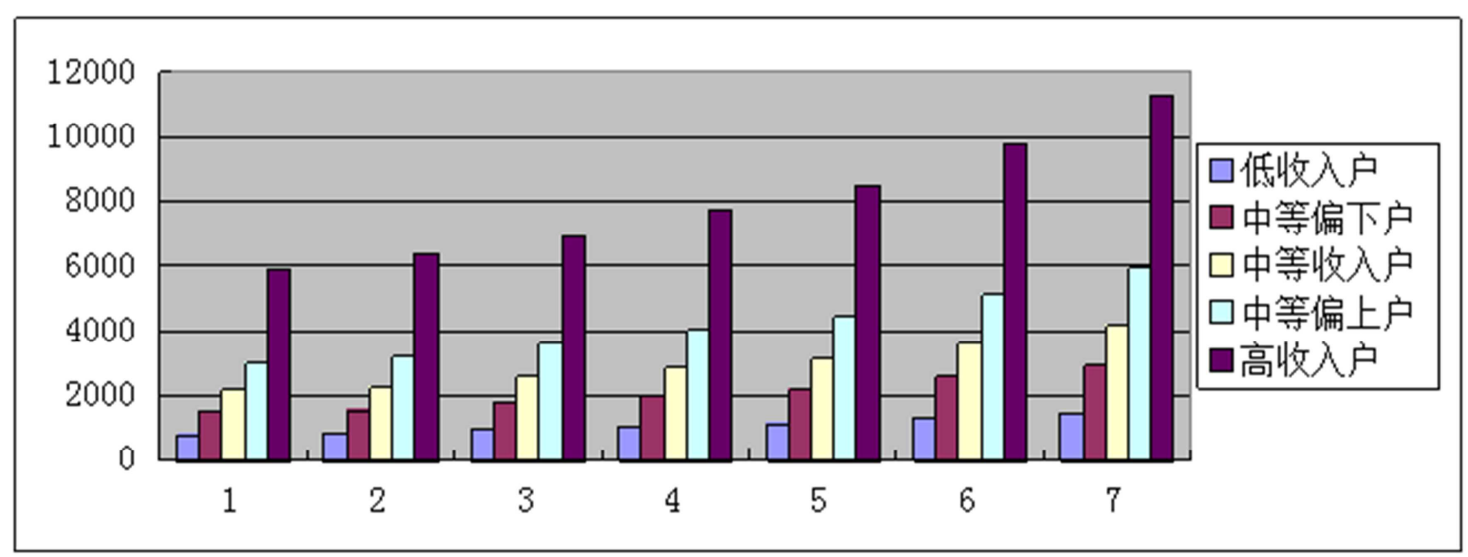

图3 2002-2008年农村按收入等级分类柱形图。

\section{2. 城乡居民受教育水平现状}

\subsection{1. 城乡居民教育投入}

中国城镇与农村都分别承担义务教育外所要花费的 教育方面的支出，但是二者之间支出的费用有着本质上的 差距。表1中，城镇在文娱教育上的花费由1990年最初的 112.26元增长到2011年的1851.74元, 增长了1739.48元, 翻了14番,一直维持着稳定的增长频率; 而农村一开始投 入差距没有与城镇相差很大，从1990年的77.97元到2011 年的725.90元, 翻了9 番, 就农村自身来说增长是显著的 但是文教娱乐支出占消费支出的比例却越来越小。

表1 城乡消费支出中文教娱乐支出所占费用对比（单位：元）。

\begin{tabular}{|c|c|c|c|c|c|c|}
\hline 指标 & & 1990 & 1995 & 2000 & 2010 & 2011 \\
\hline 城 & $\begin{array}{l}\text { 消费支 } \\
\text { 出 }\end{array}$ & 1413.94 & 4102.94 & 6147.38 & 18258.38 & 20365. 71 \\
\hline 镇 & $\begin{array}{l}\text { 文 教 娱 } \\
\text { 乐支出 }\end{array}$ & 112.26 & 331.01 & 669.58 & 1627.64 & 1851.74 \\
\hline 农 & $\begin{array}{l}\text { 消 费支 } \\
\text { 出 }\end{array}$ & 903.47 & 2138. 33 & 2652.42 & 6991.79 & 8641.63 \\
\hline 村 & $\begin{array}{l}\text { 文 教 娱 } \\
\text { 乐支出 }\end{array}$ & 77.97 & 254.68 & 385.40 & 664.22 & 725.90 \\
\hline
\end{tabular}

城镇居民家庭教育花费高于农村居民家庭教育花费 主要在于城镇家长在重视孩子的基本的教育外开始有意 识的注重教育质量以及教育内容的多元化, 使孩子得到均 衡的培养从而适应社会发展, 这方面的花费便在增长教育 支出上体现出来。在城市中, 多样的培训机构为顺应这一 发展如雨后春笋般冒出。相对来说, 农村居民对孩子教育 投入上的花费比较单一，主要是基本的一些教育费用，包 括交纳学校教育的学、杂费和购买学习用具等, 仅仅这些 对于一些困难家庭来说仍是比较沉重的负担。

\subsection{2. 城乡居民受教育年限}

从1995-2011年，总体上人均受教育年限是保持增长 的, 农村由 1995 年的人均 6.05 年增长到 2011 年的 7.95 年, 增长了 1.9 年, 农村居民人均受教育程度从小学水平提高 到初中水平; 城镇居民人均受教育年限由 1995 年的 8.34 年增长到 2011 年的 9.99 年, 增长了 1.55 年, 教育程度从初 中水平提高到高中水平。

\section{3. 实证分析}

\section{1. 变量选取与说明}

本文根据《中国人口与就业统计年鉴》和《中国统计 年鉴》公布的1996年到2011年的数据, 并对部分数据整理 计算, 最终选定变量进行分析, 具体变量的设置如下:

收入水平指标: 城乡居民人均收入

国家统计部门通常用城镇居民可支配收入来表示城 镇居民人均收入，而农村居民人均收入则用农村居民人均 纯收入来表示。

受教育水平指标: 人均受教育年限

一个地方的受教育水平的高低往往以人均受教育年 限来体现本文中将不同受教育水平以所完成学制年数分 阶层来计算, 由于中国实行的中小学九年义务教育, 一般 在小学的受教育年限为6年; 初中的按照通常完成整个阶 段的计算为9年; 高中的受教育年限也按照完成全部学业 为准, 通常取 12 年; 对于大专及以上学历的统一按照普通 的大学本科的受教育年限16年来计算。

$$
\text { 人均受教育年限 }=\frac{\text { 该地区各个受教育阶层人数乘以相对应学制年数所得数总和 }}{\text { 该地区的总人数 }}
$$

\section{2. 模型构建}

为了更清楚的分析城乡居民收入差距与受教育水平 的关系, 本文中用 $\mathrm{x}$ 表示当年的城乡教育水平, 以城乡居 民的平均受教育年限比值来表示; 用y来表示收入差距,
即城乡居民的人均收入比值。通过对 $\mathrm{x}$ 和 $\mathrm{y}$ 两个指标作散点 图, 如图4, 可以发现 $\mathrm{y}$ 与 $\mathrm{x}$ 之间呈现显著的线性关系, 则 采用线性回归分析的方法, 建立 $\mathrm{y}$ 关于 $\mathrm{x}$ 的一元线性回归模 型。其中, $\mathrm{x}$ 为城乡居民的平均受教育年限比值, $\mathrm{y}$ 城乡居 民的人均收入比值。 


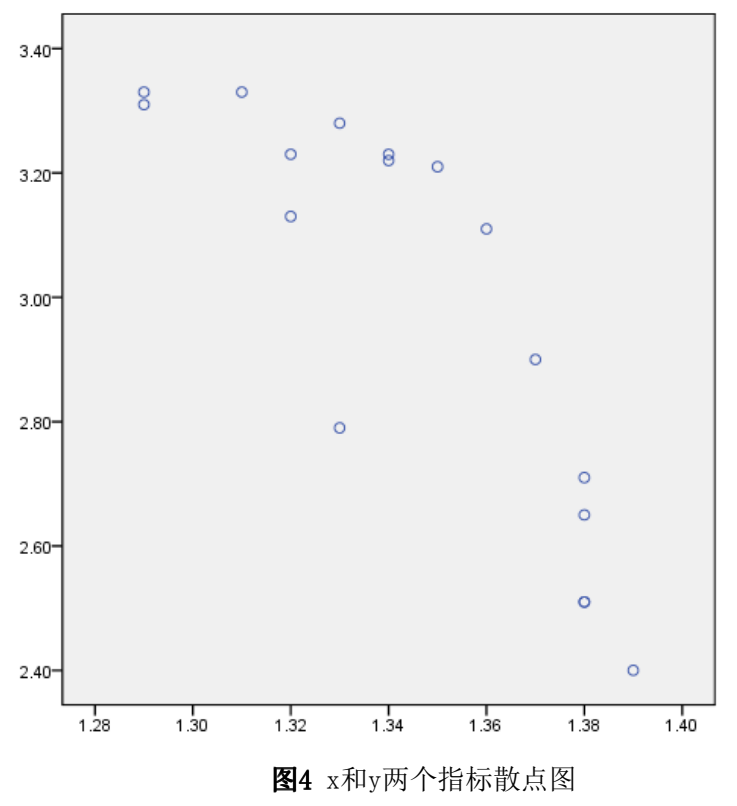

为被解释变量 $\mathrm{y}$ 与解释变量 $\mathrm{x}$ 建立一元线性回归方程 的数学模型:

$$
\mathrm{y}=\beta_{0}+\beta_{1} \mathrm{x}+\varepsilon
$$

上式中 $\beta_{0}$ 和 $\beta_{1}$ 都是模型中的未知参数, $\beta_{0}$ 和 $\beta_{1}$ 分 别称为回归常数和回归系数, $\varepsilon$ 称为随机误差, 是一个随 机变量。

\section{3. 模型的检验和分析}

在构建分析模型的研究过程中, 本文运用SPSS16.0统 计软件, 用一元回归分析法对分析模型进行一元线性回归 分析, 回归结果如下表所示。

表2 模型的拟合优度检验。

\begin{tabular}{lllll}
\hline 模型 & 判断系数 $R$ & 判断系数 $R^{2}$ & $\begin{array}{l}\text { 调整的判断 } \\
\text { 系数 } R^{2}\end{array}$ & $\begin{array}{l}\text { 回归方程的 } \\
\text { 估计标准差 }\end{array}$ \\
\hline 1 & $0.851^{\mathrm{a}}$ & 0.725 & 0.706 & 0.174 \\
a. 预测变量: (常数), 城乡人均受教育年限比值 & \\
\hline
\end{tabular}

表3 回归方程的方差分析。

\begin{tabular}{lllllll}
\hline 模型 & 平方和 & 自由度 & 均方 & $F$ 值 & $p$ 值 \\
\hline & 回归平方和 & 1.192 & 1 & 1.192 & 39.473 & $0.00^{\mathrm{a}}$ \\
1 & 剩余平方和 & 0.453 & 15 & 0.030 & & \\
& 总离差平方和 & 1.644 & 16 & & & \\
a. 预测变量: (常数), 城乡人均受教育年限比值 & & \\
b. 因变量: 城乡居民收入比值 & & & & \\
\hline
\end{tabular}

表3中各列数据项的含义依次为: 被解释变量的变差 来源、离差平方和、自由度、均方、回归方程显著性检验 中F统计量的观测值和概率p值。由表中分析结果可以看出, 总离差平方和为 1.644 , 回归平方和及均方都为 1.192 , 剩 余平方和及均方分别为 0.453 和 $0.030, \mathrm{~F}$ 统计量的观测值 为 36.473 , 对应的概率 $\mathrm{p}$ 值近似为 0 。设显著性水平 $\alpha$ 为 0. 05, 由于概率p值小于显著性水平 $\alpha$, 应拒绝回归方程
显著性检验的零假设, 认为各回归系数不同时为 0 , 被解 释变量与解释变量的线性关系是显著的, 因此, 可建立线 性模型。

表4 回归系数的显著性检验。

\begin{tabular}{|c|c|c|c|c|c|}
\hline \multirow[b]{2}{*}{ 模型 } & \multicolumn{2}{|c|}{ 未标准化系数 } & \multirow{2}{*}{$\frac{\text { 标准化系数 }}{\text { 系数 } \beta}$} & \multirow[b]{2}{*}{$\mathrm{t}$} & \multirow{2}{*}{$\begin{array}{l}\text { 显 著 } \\
\text { 性 }\end{array}$} \\
\hline & 系数B & $\begin{array}{l}\text { 系 数 标 } \\
\text { 准误 }\end{array}$ & & & \\
\hline \multirow{2}{*}{$\begin{array}{l}1 \quad \text { (常数) } \\
\text { a. 因变量: 城 }\end{array}$} & 14. 273 & 1.795 & & 7. 949 & 0.00 \\
\hline & $\begin{array}{l}-8.394 \\
\text { 居民收 }\end{array}$ & $\begin{array}{l}1.336 \\
\text { 比值 }\end{array}$ & -0.851 & -6.283 & 0.00 \\
\hline
\end{tabular}

表4中进行的是回归系数的显著性检验, 假设显著性 水平 $\alpha$ 为 0.05 , 变量的回归系数的概率都趋于 0 , 明显小 于显著性水平 $\alpha$, 因此, 城乡居民受教育水平与被解释 变量居民收入差距之间的线性关系显著, 一元线性回归方 程是:

$$
y=-8.394 x+14.273
$$

上式说明中国城乡居民收入比值与人均受教育年限 的比值是线性相关的。

\section{4. 研究结论}

由于数据统计差异和其他各方面的原因, 收入差距与 受教育之间的互相影响未明确显现, 但其理论上关系依旧 存在。城乡之间的收入存在差距, 同时它们各自内部之间 居民收入也存在差距。这些差距是不可以忽略不计的, 它 们一直不断被拉大。我们从数据中看到农村居民收入在 1990 到2011这22年间收入增长了10倍, 而城镇居民收入也 增长了 14.5 倍, 看似增长倍数差不多都是 10 多倍, 但是 2011年后者却是前者的3倍, 多出 14832.49元。教育水平 的差距也同样的明显, 农村学校设施不完善, 孩子的学习 环境艰苦, 缺乏老师, 缺少教育资金。

总的来说, 教育与收入就像太极中的两个 “鱼眼” 是 一个整体, 相辅相成。当人们接受比较高的教育水平, 人 们从社会得到的收入较高。收入增加对教育有一定促进作 用。从现在的各个家庭来看, 一般经济生活条件好的家庭, 他们的家庭成员所接受的教育程度都很高; 经济生活条件 差的家庭, 他们的家庭成员所接受的教育程度都很低。这 是很容易解释的现象, 城镇家庭拥有较高的收入, 能够满 足大多数的教育方式为孩子以后进入社会提供保证; 农村 家庭本身收入低, 还要面对生活中各方面的消费, 投入到 教育方面的就相对较少。

\section{4. 当代中国经济下的教育改革政策建议}

（1）资金流向改革。义务教育资金向农村倾斜，充足 的教育资金能够保证农村孩子都接受到义务教育, 增加学 校的硬件设施, 提高办学水平。确定社会捐赠性质对于农 村教育捐赠要确保到位, 而对于缺少关注的农村地区则要 向社会发出呼吁, 适当的补助困难家庭减免孩子的学杂费, 使得每一位适龄儿童都拥有基础教育保障。对教育的投资, 
是需要长久的且不能间断的, 政府部门应该积极地面对教 育方面的各种资金问题。

（2）教师资源改革。除了农村教育资金外，农村缺乏 教师也是一个重要问题。艰苦的环境使得农村很难留住教 师, 相对于农村, 城镇教师资源就显得过剩, 这就需要合 理的分配教师资源。一方面可以提高农村教师的工资，增 加补贴, 用以留住教育人才; 另一方面教师任教实行轮换 由农村工作后再转向城镇, 保证农村教师的充足。同时增 加农村教师接受培训的机会这就使得农村教师数量和质 量都有了保障。

(3) 教育方式改革。以往的教学方法往往都是老师在 黑板书写学生在下面接受信息再转化为自己的知识, 而现 如今是信息化时代人们只要鼠标一点就可以浏览更多的 信息, 这样就要求教育也要信息化; 通过远程教育农村学 生有机会 “面对面” 接受全国优秀教师的教学, 还可以丰 富农村教师的教学方法, 提高教学质量, 推动农村学校教 育改革。

\section{参考文献}

[1] 国家统计局. 中国统计年鉴2012[Z]. 北京: 中国统计出版 社, 2012 。
[2] 国家统计局. 中国人口与就业统计年鉴1996-2012 [Z]. 北京： 中国统计出版社, 1996-2012。

[3] 薛薇. 统计分析方法及应用 (SPSS) [M]. 北京 : 电子工业出 版社, 2009。

[4] 徐国祥. 统计预测和决策 [M]. 上海: 上海财经大学出版 社, 2008。

[5] 周琳妲. 基于教育视角的中国城乡收入差距探析 $[\mathrm{J}]$. 经济 问题研究, 2011, (5):60-66。

[6] 张艳华. 教育公共投入与收入差距的波及效应 $[\mathrm{J}]$. 公共管 理, 2011, (9) : 143-149。

[7] 杜鹏. 我国教育发展对收入差距影响的实证分析 [J]. 南开 经济研究, 2005, (4) : 47-52。

[8] 王金琦, 林丽萍. 城乡教育差距分析 $[\mathrm{J}]$. 湖南农 机, 2010, 37 (4):170-173。

[9] 冯云. 城乡教育发展差距与居民收入差距关系研究 $[\mathrm{J}]$. 当 代经济管理, 2011, 33 (10) :13-18。

[10] 裴竹梅. 城乡教育差距与城乡收入差距 $[J]$. 云南行政学院 学报, 2006,(6) : 153-156。

[11] 王云多. 受教育水平与收入差距及相关影响因素 [J]. 南京 人口管理干部学院学报, 2010, 26 (3) :42-46。 